\title{
Laporan kasus berbasis bukti Peran Bilas Surfaktan pada Neonatus Aterm dengan Sindrom Aspirasi Mekonium
}

Rinawati Rohsiswatmo, Ahmad Kautsar

Departemen Ilmu Kesehatan Anak Fakultas Kedokteran Universitas Indonesia-RSCM, Jakarta

Latar belakang. Sindrom aspirasi mekonium ditandai dengan gejala distres napas pada neonatus yang lahir dengan cairan amnion terwarna meconium dengan gejala radiologis yang khas. Mekonium dapat menghambat aktivitas dari komponen surfaktan endogen dan dapat menurunkan produksi surfaktan. Pemberian surfaktan secara bolus dapat mengganti surfaktan endogen yang telah terinaktivasi oleh asam lemak yang terdapat pada mekonium, sedangkan bilas paru dengan surfaktan dipercaya dapat membuang mekonium yang tersisa di jalan napas.

Tujuan. Mengetahui efektivitas dari bilas surfaktan pada neonatus aterm dengan sindrom aspirasi mekonium

Metode. Penelusuran pustaka database elektronik : Pubmed dan Cochrane

Hasil. Bilas surfaktan dapat menurunkan angka kematian dan penggunaan ECMO dengan RR 0,33 (IK 0,11-0,96). Tidak ada perbedaan yang bermakna dalam hal kejadian pneumotoraks (RR 0,38 IK 0,08-1,90). Bradikardi dan desaturasi dapat ditemukan sebagai efek samping.

Kesimpulan. Bilas surfaktan bermanfaat dalam menurunkan angka kematian pada bayi dengan SAM. Efek samping bilas surfaktan terjadi sementara yaitu hipoksemia dan bradikardi dan dapat kembali normal. Sari Pediatri 2018;19(6):356-63

Kata kunci: bilas surfaktan, sindrom aspirasi mekonium, neonates aterm

\section{The Effectiveness of Surfactant Lavage for Aterm Neonate with Meconium Aspiration Syndrome}

Rinawati Rohsiswatmo, Ahmad Kautsar

Background. Meconium aspiration syndrome (MAS) is defined as respiratory distress in a neonate born through meconium-stained amniotic fluid (MSAF) with characteristic radiological changes. Meconium could inactivate endogenous surfactant and decrease the activity of surfactant action and decrease its production. Bolus surfactant therapy will replace endogenous surfactant inactivated by meconium while surfactant lavage has been associated with removal of meconium from the lungs.

Objective. To evaluate the effectiveness of surfactant lavage for aterm neonate with meconium aspiration syndrome.

Result. Surfactant lavage can decrease mortality and progressive respiratory failure requiring ECMO with RR 0.33 (95\% CI 0.11-0.96). There is no significant difference of the occurrence of pneumothorax (RR $0.3895 \%$ CI 0.08-1.90). Side effects of this procedure include desaturation and bradycardia.

Conclusion. Surfactant lavage is associated with decrease mortality rate in neonate with MAS. Side effect of this procedure such as hypoxemia and bradycardia are temporary and will resume to normal. Sari Pediatri 2018;19(6):356-63

Key words:. surfactant lavage, meconium aspiration syndrome, aterm neonates 
S indrom aspirasi mekonium (SAM) pada neonatus merupakan penyakit pada saluran napas bayi cukup bulan yang ditandai dengan gejala hipoksia, hiperkapnia, dan asidosis. ${ }^{1,2}$ Penyakit ini masih merupakan salah satu masalah utama pada neonatus cukup bulan yang memberikan dampak mortalitas dan morbiditas. ${ }^{3}$ Insiden terdapatnya cairan amnion yang bercampur mekonium bervariasi pada populasi. ${ }^{1}$ Sekitar 5\% dari neonatus cukup bulan di Eropa lahir dengan cairan ketuban bercampur mekonium. Distres napas akibat SAM terjadi pada 1 sampai 2 dari 1000 kelahiran hidup. Walaupun tidak diketahui secara pasti, angka kejadian SAM lebih tinggi pada negara berkembang. ${ }^{4}$

Mekonium merupakan substansi yang terdiri dari air, lanugo, sel yang berdeskuamasi, verniks, cairan amnion, enzim pankreas, dan pigmen empedu. ${ }^{1}$ Aspirasi mekonium pada jalan napas dapat menyebabkan obstruksi, vasokonstriksi pembuluh darah paru, hipertensi paru, disfungsi surfaktan, infeksi, dan pneumonitis. ${ }^{1}$ Sindrom SAM merupakan kumpulan berbagai gejala klinis dan radiologis akibat janin atau neonatus tidak sengaja menghirup atau mengaspirasi mekonium. ${ }^{5}$ Tatalaksana dari SAM umumnya bersifat suportif. Prinsip utama dari tatalaksana pada SAM adalah mempertahankan oksigenasi adekuat, tekanan darah yang optimal, dan koreksi dari kelainan metabolik yang menyertai seperti asidosis dan hipoglikemia. ${ }^{1}$

Mekonium dapat menghambat aktivitas dari komponen surfaktan endogen sehingga menurunkan efektivitas kerja surfaktan. Surfaktan adalah campuran dari fosfolipid, lipid, dan protein yang berperan dalam menurunkan tekanan permukaan pada alveolus. ${ }^{6}$ Studi pada hewan coba menunjukkan bahwa bilas surfaktan pada jalan napas dapat mengeluarkan mekonium dari paru yang berakibat pada perbaikan fungsi paru. ${ }^{7}$ Surfaktan dapat diberikan melalui intratrakeal secara bolus atau bentuk diencerkan yang berfungsi sebagai bilas paru pada neonatus dengan SAM. Pemberian secara bolus dipikirkan dapat mengganti surfaktan endogen yang telah terinaktivasi oleh asam lemak yang terdapat pada mekonium, sedangkan bilas paru dengan surfaktan dipercaya dapat membuang mekonium yang tersisa di jalan napas. ${ }^{8}$ Laporan kasus berbasis bukti ini bertujuan untuk membuktikan efektivitas dari bilas surfaktan pada neonatus aterm dengan sindrom aspirasi mekonium.

\section{Kasus}

Seorang bayi perempuan usia gestasi 39-40 minggu berat lahir 3020 gram, lahir secara bedah Kaisar atas indikasi fetal distress dan ketuban pecah dini. Bayi lahir menangis lemah, merintih, kurang aktif, dengan apgar skor 6/8. Warna ketuban saat lahir hijau kental. Setelah dilakukan resusitasi awal, saturasi oksigen pada menit ke-10 tidak dapat lebih dari 72\%. Pasien kemudian diputuskan dilakukan intubasi dan pembilasan bronkus dengan larutan salin. Klinis perbaikan setelah tindakan dan diputuskan untuk dilakukan ekstubasi dan ditransfer ke Neonatal Intensive Care Unit (NICU) dengan Single nasal prong dengan Positive end expiratory pressure (PEEP) 7 dan fraksi inspirasi oksigen (FiO2) 21\%.

Pada usia 2 jam, bayi terdapat retraksi berat, takipnea, dan desaturasi sampai $80 \%$. Hasil pemeriksaan analisis gas darah kapiler menunjukkan asidosis respiratorik dengan $\mathrm{pH} 7,25, \mathrm{pCO} 251$ $\mathrm{mmHg}, \mathrm{HCO} 322 \mathrm{Meq} / \mathrm{L}$, dan base excess -5 . Bantuan napas saat itu menggunakan Non-invasive ventilation (NIV). Bayi kemudian diputuskan untuk diintubasi dan bantuan napas diambil alih ventilator konvensional dengan setting PC/AC 30/5 rate 60x/menit dan $\mathrm{FiO} 2$ $40 \%$. Bayi masih terdapat desaturasi sampai $40 \%$ dengan bantuan ventilator, kemudian diputuskan untuk dilakukan pemasangan High Frequency Osscilatory ventilation (HFO) dimulai dari setting PAW 13, amplitude 30, frekuensi 8, dan $\mathrm{FiO} 2$ 100\%. Klinis bayi mulai stabil (tidak ada retraksi dinding dada, tidak sianosis, dan saturasi oksigen 95-98\%) pada PAW 17, amplitude 30 frekuensi 8 FiO2 30\%.

Bayi kemudian dilakukan bilas surfaktan. Satu flaccon surfaktan dilarutkan dengan $\mathrm{NaCl} 0,9 \%$ sampai dengan $30 \mathrm{ml}$. Cairan kemudian dimasukkan melalui ETT dengan cepat, dilakukan bagging selama 1-2 menit, kemudian dilakukan penghisapan. Cairan yang keluar setelah penghisapan merupakan cairan kental berwarna putih kehijauan. Bilas dilakukan selama 2 kali. Setelah dilakukan bilas surfaktan, setting HFO dapat diturunkan. Amplitudo dapat diturunkan menjadi 23 dan $\mathrm{FiO} 2$ sampai $21 \%$. Pada pemeriksaan darah perifer lengkap didapatkan: $\mathrm{Hb} 16,7 \mathrm{mg} / \mathrm{dL}$, ht $49,1 \%$, leukosit $27.170 / \mathrm{mm}^{3}$, Trombosit $218.000 /$ $\mathrm{mm}^{3}$. Pemeriksaan marker infeksi menunjukkan tidak ada peningkatan ditandai dengan nilai CRP $5 \mathrm{mg} / \mathrm{dL}$ dan ratio neutrofil matur:imatur sebesar 0,19. Pada pemeriksaan ekokardiografi didapatkan Persistent 
pulmonary hypertension (PPHN) dan Persistent ductus arteriosus (PDA). Bayi kemudian diberikan inhalasi illoprost 2,5 mcg setiap 6 jam, antibiotik lini pertama, dan surfactant replacement. Bayi dapat disapih dari ventilator pada usia 72 jam dan dapat rawat jalan pada usia 5 hari.

Bayi usia gestasi 39-40 minggu dan berat lahir 3020 gram dengan sindroma aspirasi mekonium, dilakukan bilas surfaktan melalui endotracheal tube (ETT). Setelah dilakukan tindakan bilas surfaktan, klinis respirasi perbaikan dan bayi dapat cepat disapih dari ventilator.

Kasus tersebut menimbulkan pertanyaan klinis sebagai berikut: Bagaimana efektivitas bilas surfaktan pada neonatus cukup bulan dengan sindrom aspirasi mekonium dibandingkan dengan terapi standar?

\section{Metode}

Untuk menjawab masalah di atas, prosedur pencarian pustaka dilakukan dengan menelusuri literatur secara online menggunakan instrumen pencari Pubmed, Cochrane, dan Highwire. Kata kunci yang digunakan adalah "surfactant lavage or surfactant bolus", "meconium aspiration syndrome", "neonate or newborn ", dengan menggunakan batasan, bahasa pengantar adalah bahasa Inggris, publikasi dalam rentang waktu 10 tahun terakhir, serta penelitian dengan penelitian uji coba klinis, telaah sistematik atau meta analisis. Berdasarkan metode penelusuran dengan kriteria di atas, didapatkan 17 artikel, tetapi setelah ditelaah lebih lanjut terdapat 2 artikel yang dianggap relevan dengan masalah. Levels of evidence ditentukan berdasarkan klasifikasi yang dikeluarkan oleh Oxford Centre for Evidence-Based Medicine. ${ }^{6}$ Artikel yang terpilih adalah penelitian telaah sistematik dan meta analisis.

\section{Hasil penelusuran literatur}

\section{Telaah Sistematis (Levels of evidence 1)}

Choi $\mathrm{dkk}^{9}$ melakukan telaah sistematis pada tahun 2012 untuk menilai efektivitas dari terapi bilas surfaktan pada neonatus dengan SAM. Penelitian yang diinklusi dalam telaah sistematis ini adalah uji acak terkontrol dan uji klinis tidak acak yang didapatkan melalui penelusuran MEDLINE (1959-2012), EMBASE (1980-2012), dan
CENTRAL (2010-2012). Telaah sistematis ini juga melakukan penyaringan dari abstrak yang dipublikasi sejak tahun 2010 sampai Juni 2010 di Pediatric Research atau dari rapat yang dilakukan oleh Pediatric Academic Societies. Luaran yang dinilai pada penelitian ini antara lain mortalitas, kebutuhan dari Extracorporeal Membrane Oxygenation (ECMO), airleaks (pneumothoraks, emfisema paru, pneumomediastinum, dan pneumopericardium), lama dari penggunaan ventilator mekanis, lama dari penggunaan oksigen, dan lama rawat. Data pada studi ini dinilai dan diolah oleh minimal 2 peninjau mandiri dan setiap perbedaan pendapat didiskusikan antar penulis. Pada penelusuran literatur didapatkan 10 studi: 2 studi merupakan uji klinis acak terkontrol, ${ }^{10,11}$ dan 8 studi merupakan uji klinis tidak acak. ${ }^{12-19}$ Pada beberapa studi (2 studi uji klinis acak terkontrol dan 2 uji klinis tidak acak), bolus surfaktan diberikan jika diperlukan, tanpa melihat grup perlakuan. ${ }^{10-11,15,19}$ Studi yang dilakukan analisis pada telaah sistematik ini secara klinis heterogen dalam hal derajat keparahan penyakit, metode dari pemberian surfaktan, waktu pemberian surfaktan awal, dan modalitas terapi kombinasi lainnya.

Hasil telaah sistematis ini menunjukkan bilas surfaktan menurunkan angka kematian atau kebutuhan ECMO pada kedua uji klinis acak terkontrol dengan relative risk (RR) 0,34 dan interval kepercayaan (IK) 0,11-0,99 dan pada uji klinis tidak acak memiliki RR sebesar 0,35 dengan IK 0,13-0,94. Semua studi, kecuali yang dilakukan oleh Schlosser dkk, ${ }^{16}$ secara konsisten menunjukkan hasil yang mendukung bilas surfaktan dalam hal menurunkan angka kematian atau kebutuhan akan ECMO. Hampir semua studi menunjukkan tidak didapatkan subjek yang meninggal kecuali pada studi yang dilakukan oleh Wiswell dkk, ${ }^{10}$ Lee dkk, ${ }^{17}$ dan Kowalska dkk. ${ }^{18}$ Angka kejadian pneumotoraks tidak berbeda bermakna secara statistik pada kedua RCT, namun menurun angkanya pada kelompok terapi dan bermakna secara statistik pada uji klinis tidak acak. Lama penggunaan ventilator mekanik lebih singkat pada semua studi kecuali studi uji klinis tidak acak yang dilakukan oleh Dargaville ${ }^{15}$ dan Kowalska. ${ }^{18}$ Lama dari penggunaan oksigen tidak berbeda bermakna pada kedua uji klinis acak namun menunjukkan penggunaan yang lebih singkat 
sampai lebih dari 10 hari pada beberapa uji klinis tidak acak. ${ }^{12,19}$ Sebagian besar studi menunjukkan lama rawat yang lebih singkat pada kelompok perlakuan kecuali satu uji klinis tidak acak yang dilakukan oleh Salvia-Rogers. ${ }^{14}$ Hasil dari keluaran yang dinilai dapat dilihat pada tabel 3 dan tabel 4.

\section{Telaah Sistematis (Levels of evidence 1)}

Telaah sistematis yang kedua dilakukan oleh Hahn $\mathrm{dkk}^{20}$ pada tahun 2012. Tujuan dari telaah sistematis ini adalah untuk menilai efek dari bilas paru pada morbiditas dan mortalitas neonatus dengan SAM. Studi ini juga melakukan analisis subgrup dalam hal jenis cairan bilas/lavage yang digunakan, waktu yang tepat untuk dilakukan terhadap mortalitas dan morbiditas nonatus dengan SAM. Penelitian yang diinklusi adalah semua uji klinis acak atau quasi-randomised yang membandingkan bilas paru dengan terapi standar pada neonatus dengan SAM. Penelitian yang termasuk dalam studi ini dipublikasi sejak tahun 1966 sampai Desember tahun 2012 dan terdapat pada database Cochrane, CENTRAL, MEDLINE, dan EMBASE. Neonatus dengan SAM baik yang sudah diintubasi sebelum perlakuan atau diintubasi untuk dilakukan perlakuan dimasukkan dalam studi ini. Bilas paru didefinisikan sebagai setiap tindakan memasukkan cairan ke paru yang kemudian diikuti dengan usaha untuk mengeluarkannya melalui tindakan penghisapan (suction), drainase postural, atau keduanya. Cairan yang digunakan dapat berupa salin, surfaktan utuh atau yang telah diencerkan, dan perfluorokarbon. Terapi standar didefinisikan sebagai terapi tanpa dilakukannya bilas paru namun tetap mencakup penghisapan rutin pada selang endotrakea untuk mempertahankan patensinya. Luaran primer yang dinilai adalah kematian, penggunaan ECMO, pneumotoraks, airleaks, lama penggunaan ventilator mekanik, lama penggunaan oksigen, lama rawat di rumah sakit, dan total biaya rawat di rumah sakit. Luaran sekunder yang dinilai berupa indeks fungsi paru (indeks oksigenasi, beda oksigen alveolar-arteri $\left(\mathrm{AaDO}_{2}\right)$, rasio fungsi paru) yang diukur pada usia 24, 48, dan 72 jam serta efek samping dari pembilasan (hipoksemia akut, bradikardia, dan hipotensi). Data pada studi ini dinilai dan diolah oleh minimal 2 peninjau mandiri dan setiap perbedaan pendapat didiskusikan antar penulis. Dari penelusuran literatur terdapat 3 penelitian yang masuk kriteria, yakni penelitian yang dilakukan oleh Wiswell dkk, ${ }^{10}$ Gadzidowski dkk, ${ }^{21}$ dan Dargaville dkk. ${ }^{11}$ Uji Klinis Acak Terkontrol (Levels of evidence 1)

Wiswell $\mathrm{dkk}^{10}$ melakukan uji klinis acak terkontrol bilas surfaktan pada bayi yang terntubasi dengan SAM dengan usia gestasi minimal 35 minggu dan usia kurang dari 72 jam. Subjek penelitian memiliki indeks oksigenasi diantara 8 sampai 25 pada dua pemeriksaan analisis gas darah yang terpisah dalam kurun waktu 3 jam. Bilas surfaktan dilakukan pada usia rerata 14 jam dengan 6 aliquot dengan masing-masing $8 \mathrm{ml} / \mathrm{kg}$ surfaktan (surfaxin). Konsentrasi surfaktan yang digunakan adalah $2,5 \mathrm{mg} / \mathrm{ml}$ untuk 4 aliquot pertama dan $10 \mathrm{mg} / \mathrm{ml}$ untuk aliquot terakhir. Setiap aliquot dimasukkan melalui selang ETT saat tekanan akhir ekspirasi (PEEP) diberikan, kemudian diikuti dengan penghisapan selama 10 detik. Tanda vital ditunggu sampai kembali normal sebelum pemberian aliquot berikutnya. Setelah akhir pemberian aliquot, tekanan akhir ekspirasi dipertahankan 6 sampai $8 \mathrm{~cm} \mathrm{H}_{2} 0$ selama 2 jam. Subjek kontrol menerima ventilasi mekanik konvensional dan terapi standar sesuai protokol. Kegagalan terapi pada kedua kelompok didefinisikan bila indeks oksigenasi $(\mathrm{OI})>25$ atau OI diatas $50 \%$ dari nilai normal. Pasien dengan gagal terapi mendapat kan ventilasi dengan High frequency Oscillator (HFO), terapi bolus surfaktan, inhalasi nitrik oksida, dan ECMO.

3. Uji Klinis Acak Terkontrol (Levels of evidence 1) Dargaville $\mathrm{dkk}^{11}$ melakukan uji klinis acak terkontrol multisenter tentang penggunaan bilas surfaktan pada bayi dengan SAM. Subjek penelitian adalah bayi dengan minimal usia gestasi 36 minggu, berat badan $2 \mathrm{~kg}$, dan menggunakan ventilasi mekanik dengan mean airway pressure minimal $12 \mathrm{~cm} \mathrm{H}_{2} 0$ dan beda $\mathrm{O}_{2}$ arterial-alveolar setidaknya $450 \mathrm{mmHg}$ pada dua pemeriksaan analisis gas darah. Bilas surfaktan dilakukan pada rerata usia 13 jam menggunakan dua aliquot surfaktan sapi (survanta) sebanyak $15 \mathrm{ml} / \mathrm{kg}$. Surfaktan diencerkan dengan konsentrasi 5 $\mathrm{mg} / \mathrm{ml}$ dan diberikan melalui kateter selama 20 detik. Saat pemberian surfaktan, ventilator 
tidak tersambung. Setelah pemberian surfaktan, ventilasi tekanan positif diberikan sebanyak tiga kali kemudian diikuti dengan penghisapan dari cairan bilasan. Subjek kontrol mendapat terapi suportif standar dan ventilasi mekanik. Pada kedua grup, penggunaan $\mathrm{HFO}$, iNO, dan terapi surfaktan bolus merupakan keputusan dari peneliti begitu pula dengan penggunaan ECMO.

\section{Uji Klinis Acak Terkontrol (Levels of evidence 1)} Gadzinowski dkk ${ }^{21}$ melakukan uji klinis dari bilas surfaktan yang kemudian diikuti dengan terapi surfaktan bolus yang dibandingkan dengan terapi surfaktan bolus saja pada bayi SAM dengan hipertensi paru. Usia bayi setidaknya 35 minggu dan kurang dari $24 \mathrm{jam}$. Diagnosis hipertensi paru berdasarkan parameter ekokardiografi standar. Bilas surfaktan dilakukan dengan total volume 15 $\mathrm{ml} / \mathrm{kg}$ dan volume aliquot $3,75 \mathrm{ml} / \mathrm{kg}$ pada rerata usia 9,7 jam. Surfaktan yang diberikan adalah surfaktan sapi yang diencerkan (survanta) dengan konsentrasi $5 \mathrm{mg} / \mathrm{mL}$. bilas dan suction dilakukan melalui sistem tertutup pada 4 posisi : sisi kanan, sisi kiri, trendelenburg, dan anti-Trendelenburg. Setelah pembilasan, satu dosis bolus dari surfaktan (survanta, $100 \mathrm{mg} / \mathrm{kg}$ ) diberikan. Kelompok kontrol mendapatkan satu dosis surfaktan bolus (survanta, $100 \mathrm{mg} / \mathrm{kg}$ ) dan terapi konvensional. Setelah dilakukan ekokardiografi, iNO diberikan pada kedua kelompok.

Hasil telaah sistematik ini dibagi dalam dua perlakuan, yaitu : perbandingan antara bilas surfaktan dengan terapi standar, dan bilas surfaktan dengan bolus surfaktan diikuti dengan bolus surfaktan. Perbandingan perlakuan pertama antara bilas surfaktan dengan terapi standar menggunakan studi yang dilakukan oleh Dargaville dkk ${ }^{11}$ dan Wiswell. ${ }^{10}$ Berdasarkan kedua studi ini penggunaan bilas surfakatan dapat mencegah terjadinya kematian dengan RR 0,42 (95\% IK 0,12$0,46)$. Tidak ada perbedaan dalam hal penggunaan ECMO, namun hasil penelitian menunjukkan hasil yang positif (RR 0,21 IK 0,04-1,86). Jika kedua luaran ini digabung (kematian dan penggunaan ECMO), maka bilas surfaktan dapat menurunkan angka kematian dan penggunaan ECMO dengan RR 0,33 (IK 0,11-0,96). Tidak ada perbedaan yang bermakna dalam hal kejadian pneumotoraks (RR 0,38 IK 0,08$1,90)$. Lama penggunaan oksigen lebih singkat pada kelompok perlakuan di kedua studi. Pada studi yang dilakukan oleh Wiswell dkk, ${ }^{10}$ lama rawat di rumah sakit berbeda sedikit pada kelompok bilas surfaktan (12,7 hari dan 13,1 hari), sedangkan pada studi yang dilakukan oleh Dargaville dkk, ${ }^{11}$ lama rawat pasien tidak berbeda (14 hari). Kedua RCT melaporkan indeks oksigenasi (OI) yang diukur pada usia ke-24, 48, dan 72 jam setelah bilas surfaktan. Perbedaan bermakna ditemukan setelah 48 jam pada kedua kelompok. $\mathrm{AaDO}_{2}$ dan fungsi paru hanya diukur pada studi yang dilakukan oleh Dargaville $\mathrm{dkk}^{11}$ dan tidak menunjukkan perbedaan bermakna antara kedua kelompok.

Pada studi yang dilakukan oleh Wiswell dkk, ${ }^{10}$ dua bayi mengalami hipoksemia berat yang menyebabkan prosedur tindakan ditunda. Sebanyak 5 dari 15 bayi membutuhkan ventilasi tekanan positif setelah prosedur untuk menaikkan saturasi. Satu bayi mengalami hipotensi setelah bilas, namun bayi tersebut juga mengalami sepsis akibat bakteri gram negatif. Pada studi yang dilakukan oleh Dargaville dkk, ${ }^{11}$ dua bayi mengalami bradikardia transien yang membaik setelah prosedur selesai. Lima bayi mengalami desaturasi di bawah $80 \%$ selama lebih dari 10 menit, yang kembali membaik diatas 90\% dalam 40 menit pada semua kasus. Satu bayi dilaporkan meninggal akibat hipertensi pulmonal berat tiga jam setelah tindakan.

Hanya satu studi yang membadingkan antara bilas surfaktan dengan surfaktan bolus sebagai terapi standar pada pasien SAM dengan hipertensi pulmonal. Gadzinowski dkk ${ }^{21}$ melaporkan tidak ada perbedaan dalam hal angka kematian (RR 0,17 IK 0,01-3,06) dan kejadian pneumotoraks (RR 0,17 IK 0,01-3,06). Rerata lama penggunaan ventilator hanya berbeda 1 hari pada kelompok perlakuan $(6,6 \pm 2,6$ hari vs 7,3 $\pm 1,7$ hari). Lama rawat lebih singkat pada kelompok perlakuan $(16,4 \pm 5,4$ hari vs $19,8 \pm 2,9$ hari). Selain terjadinya pneumotoraks dan kematian, tidak ada efek simpang lain yang dilaporkan.

\section{Pembahasan}

Bilas paru didefinisikan sebahai setiap prosedur memasukkan cairan ke paru diikuti dengan usaha untuk mengeluarkan cairan tersebut melalui penghisapan atau drainase postural. Bilas paru sebagai prosedur terapi telah digunakan pada berbagai penyakit diantaranya fibrosis kistik, acute respiratory distress syndrome 
(ARDS), lipoid pneumonia, dan SAM.22 Bilas paru pada SAM dapat membuang mekonium yang sudah masuk ke saluran napas sehingga dapat mencegah perburukan lebih lanjut dan memperbaiki pertukaran gas dan mekanik paru. ${ }^{7}$ Awalnya cairan yang digunakan untuk membilas adalah cairan salin isotonik. Namun, cairan ini memiliki tekanan permukaan yang tinggi sehingga lebih mudah mengendap pada paru dan menyebabkan takipnea transien pada bayi. ${ }^{23}$

Studi pada hewan coba menunjukkan bilas surfaktan dapat memperbaiki oksigenasi dan faal paru dibandigkan dengan terapi surfaktan bolus. ${ }^{24}$ Prosedur ini relatif aman dilakukan pada hewan coba dan efek yang terjadi adalah penurunan saturasi oksigen yang terjadi singkat dan dapat ditoleransi. ${ }^{25}$ Studi pada manusia menunjukkan bilas surfaktan dapat menurunkan angka kematian dan penggunaan ECMO pada bayi dengan SAM. ${ }^{9,20}$

Meta-analisis yang membandingkan bilas surfaktan dan terapi standar (Wiswell 2002, Dargaville 2011), menunjukkan bahwa bilas surfaktan dapat menurunkan penggunaan ECMO dan kematian. Analisis lebih lanjut menekankan ketersediaan ECMO pada suatu pusat kesehatan sangat berpengaruh terhadap terjadinya kematian. Walaupun luaran lain yang dinilai pada uji klinis tersebut tidak bermakna secara statistik, hasil penelitian menunjukkan bahwa bilas surfaktan memberikan tren yang positif dan bermanfaat. Pada kedua telaah sistematis yang ada, hanya ada dua uji klinis acak yang tersedia dengan jumlah sampel kurang dari 100. Hal ini dapat menjadi kelemahan sebagai sumber bukti yang sahih, namun berdasarkan hasil penelitian yang ada, bilas surfaktan memberikan efek yang bermanfaat. ${ }^{9,20}$

Karena uji klinis acak tidak cukup banyak, telaah sistematis pertama mencoba memasukkan uji klinis tidak acak untuk dianalisis. Beberapa uji klinis tidak acak yang dimasukkan menggunakan kontrol retrospektif yang memiliki bias yang tinggi. Bias seleksi juga tinggi bila uji klinis tidak acak ini menggunakan kelompok kontrol tidak pada waktu yang sama dengan kelompok perlakuan. Meskipun begitu, hasil yang didapatkan pada uji klinis tidak acak konsisten dengan hasil yang didapat pada uji klinis acak. Pada uji klinis tidak acak, berdasarkan hasil meta-analisis, bilas surfaktan memiliki efek yang signifikan terhadap kejadian pneumotoraks, air leaks, kematian, dan kebutuhan akan ECMO. ${ }^{9}$

Waktu dilakukannya pembilasan dapat mem- engaruhi hasil pada beberapa studi. Intervensi yang lebih awal secara teori lebih efektif. Perubahan patologis terjadi setelah 1 jam terjadinya aspirasi dan puncak kerusakan paru terjadi pada 12-24 jam pada penelitian hewan coba. ${ }^{26}$ waktu diberikannya surfaktan pada studi yang ada berkisar antara 3 sampai 30 jam. Pemberian surfaktan pada uji klinis acak lebih lama dibandingkan uji klinis tidak acak. Keterlambatan ini dapat disebabkan karena proses randomisasi dan permintaan izin kepada orang tua yang membutuhkan waktu. ${ }^{9}$

Hasil kedua uji klinis acak yang ada, subjek penelitian pada satu studi memiliki SAM yang lebih ringan jika menggunakan indeks oksigenasi (OI). Hasil studi pada SAM yang lebih ringan menunjukkan kecenderungan ke arah berkurangnya durasi penggunaan ventilasi mekanik pada kelompok surfaktan dan tidak ada subjek yang meninggal pada kelompok surfaktan. Pada studi yang menggunakan subjek dengan derajat SAM yang lebih berat, tidak ditemukan efek yang bermakna jika dibandingkan dengan kelompok kontrol. Namun, kelompok surfaktan memiliki jumlah subjek yang meninggal lebih sedikit. Hal ini menunjukkan intervensi bilas surfaktan ini dapat dipengaruhi oleh derajat penyakit. ${ }^{9}$

Berbeda dengan pemberian surfaktan bolus, bilas surfaktan dapat menghasilkan distribusi surfaktan yang merata pada paru. Uji klinis awal pada pemberian bolus surfaktan dengan dosis tinggi menunjukkan angka penurunan risiko penggunaan ECMO. Pada studi yang dilakukan di pusat yang tidak memiliki ECMO, tidak ada perbedaan bermakna antara penggunaan bolus surfaktan dengan terapi standar dalam hal kematian, pneumotoraks, dan lama penggunaan ventilator. Hal ini membuat beberapa peneliti tidak menggunakan bolus surfaktan sebagai terapi standar pada kelompok kontrol. ${ }^{11}$

Walaupun beberapa studi menunjukkan efek yang positif, keamanan dari prosedur ini masih dipertanyakan. Volume pemberian yang banyak dapat mengeksaserbasi terjadinya hipoksia dan menyebabkan kematian pada pasien dengan SAM berat dan hipertensi paru. ${ }^{27}$ Pada beberapa uji klinis tidak acak, dilaporkan terjadinya hipoksemia sementara, bradikardi atau hipotensi yang umumnya dapat pulih dalam beberapa saat dan tidak membutuhkan intervensi lebih lanjut. Pada satu uji klinis acak, 1 pasien meninggal karena hipertensi pulmonal intraktabel 3 jam setelah bilas. ${ }^{11}$ Pasien pada uji klinis acak mendapatkan volume cairan 
Rinawati Rohsiswatmo dkk: Peran bilas surfaktan pada neonatus aterm dengan sindrom aspirasi mekonium

yang lebih banyak dibandingkan pada uji klinis tidak acak. Hal ini mungkin menjadi alasan timbulnya kejadian serius yang lebih sering pada uji klinis acak. ${ }^{9}$

Studi yang membandingkan antara bilas surfaktan dengan bolus surfaktan tidak menunjukkan efek yang bermakna dalam hal kematian, pneumotoraks, lamanya penggunaan ventilator, dan lama rawat. Intervensi bilas surfaktan pada studi ini, tampaknya memperbaiki oksigenasi pada 24 jam pertama. ${ }^{20}$ Dari sedikit uji klinis acak yang ada, hanya satu yang memiliki risiko bias yang rendah. Studi lain dibutuhkan untuk menilai efek bilas surfaktan dengan sampel yang lebih banyak dan melakukan analisis terhadap jenis cairan, volume aliquot cairan, dan waktu pemberian cairan. ${ }^{20}$

\section{Kesimpulan}

Bilas surfaktan bermanfaat dalam menurunkan angka kematian pada bayi dengan SAM. Efek samping bilas surfaktan terjadi sementara yaitu hipoksemia dan bradikardi dan dapat kembali normal.

\section{Saran}

Uji klinis yang dilakukan sebelumnya pada penelitian menggunakan sampel yang relatif sedikit $(<100)$. Untuk menarik kesimpulan yang lebih sahih, penelitian dengan jumlah sampel yang lebih besar sangat diperlukan

\section{Daftar pustaka}

1. Dargaville PA. Respiratory support in meconium aspiration syndrome : a practical guide. Int J of Ped 2012;1:1-9.

2. Yeh TF. Meconium aspiration syndrome: pathogenesis and current management. Pediatr Rev 2011;11:e503-11.

3. Ulah A. Surfactant therapy in meconium aspiration syndrome (MAS). J Obstet Gynecol Barpeta 2014;1:24-9.

4. Dargaville PA, Copnell B. Australian and new Zealand neonatal network : The epidemiology of meconium aspiration syndrome : Incidence, risk factors, therapies, and outcome. Pediatrics 2006;117:1712-21.

5. Kosim MS, Infeksi neonatal akibat ketuban keruh. Sari Pediatri 2009;11: 212-8.

6. Guttentag S, Foster CD. Update in surfactant therapy. Pediatr Rev 2011;11:e 625-33.
7. Dargaville PA. Innovation in surfactant therapy I : surfactant lavage and surfactant administration by fluid bolus using minimally invasive technique. Neonatology 2012;101:326-36.

8. Swamam K, Soraisham AS, Sivanandan S. Advances in the management of meconium aspiration syndrome. Int J Pediatr 2012;2012:1-7.

9. Choi HJ, Hahn S, Lee J, Park B, Lee MS, dkk. Surfactant lavage therapy for meconium aspiration syndrome: a systematic review and meta-analysis. Neonatology 2012;101:183-91.

10. Wiswell TE, Knight GR, Finner NN, Donn SM. Desai H, dkk. A multicenter randomized controlled trial comparing surfaxin (lucinactant) lavage with standard care for treatment of meconium aspiration syndrome. Pediatrics 2002;109:10817.

11. Dargaville PA, Copnell B, Mills JF, Haron I, Lee JK, dkk. Randomized controlled trial of lung lavage with dilute surfactant for meconium aspiration syndrome. J Pediatr 2011;158:383-89.

12. Lam BC, Yeung CY. Surfactant lavage for meconium aspiration syndrome: a pilot study. Pediatrics 1999;103:1014-18.

13. Chang HY, Hsu CH, Kao HA, Hung HY, Chang JH, dkk. Tretment of severe meconium aspiration syndrome with dilute surfactant lavage. J Formos Med Assoc 2003;102:326-30.

14. Salvia-Roiges MD, Carbonell-estrany X, Figueras Aloy J, Rodriguez-Miguelez JM. Efficacy of three treatment schedules in severe meconium aspiration syndrome. Acta Pediatr 2004;93:60-5.

15. Dargaville PA, Mills JF, Copnell B, Loughnan PM, McDougall PN, dkk. Therapeutic lung lavage in meconium aspiration syndrome: a preliminary report. J Paediatr Child Health 2007;43:539-45.

16. Schlosser RL, Veldman A, Fischer D, Allendorf A, von Loewenich V: lavage with exogenous surfactant in neonatal meconium aspiration syndrome. Z Geburtschilfe Neonatol 2002;206:15-8.

17. Lee SM, Kim HM, Jeon JH, Park MS, Park KI, dkk. Effect of surfactant lavage in severe meconium aspiration syndrome. Korean J Pediatr 2008;51-367-71.

18. Kowalska K, Szymankiewicz M, Gadzinowski J: an effectiveness of surfactant lung lavage in meconium aspiration syndrome treatment-preliminary report. Przeglad Lekarski 2002;59:21-4.

19. Kawano T. Effect of surfactant lavage to the babies with meconium aspiration syndrome. Acta Neonatol Jpn 1999;35:32-40.

20. Hahn S, Choi HJ, Dargaville P. Lung lavage for meconium aspiration syndrome in newborn infants. Coch Database Systematic Review 2013;4:1-31.

21. Gadzinowski J, Kowalska K, Vidyagasar D. Treatmen of MAS with PPHN using combined therapy: SLL, bolus surfactant 
and iNO. J Perinatol 2008;28:56-66.

22. Paschen C, Reite K, Stanzel F, Teschler H, Griese M. Therapeutic lung lavage in children and adults. Respire Res 2005;6:138.

23. Carson BS, Losey RW, Bowes WAJ, Simmons MA. Combined obstetric and pediatric approach to prevent meconium aspiration syndrome. Am J Obstet Gynecol 1976;126712-5.

24. Cochrane CG, Revak SD. Meritt TA, Schraufstatter IU, Hoch RC, dkk. Bronchoalveolar lavage with KL4-surfactant in models of meconium aspiration syndrome. Pediatr Res
1998;28:18-23.

25. Dargaville PA, mills JF, Headley BM, Chan Y, Coleman L. Therapeutic lung lavage in the piglet model of meconium aspiration syndrome. Am J resoir Crit Care Med 2003;168:45663.

26. Cleary GM, Antunes MJ, Ciesielka DA, Higins ST, Spitzer AR. Exudative ling injury is associated with decreased levels of surfactant proteins in a rat model of meconium aspirations. Pediatrics 1997;100:998-1003.

27. Kattwinkel J. Surfactant lavage for meconium aspiration syndrome: aword of caution. Pediatrics 2002;109-1167-8. 